\title{
Eğitimde Medya Okuryazarlığı ile ilgili Araştırmalara Yönelik Bibliyometrik Bir Analiz
}

DOI: $10.26466 /$ opus. 935547

\author{
* \\ Erkan Yeşiltaş ${ }^{*}-$ Ayşegül Yılmazer ** \\ ${ }^{*}$ Doç. Dr., Sivas Cumhuriyet Üniversitei, Sivas/Türkiye \\ E-Posta: eyesiltas@cumhuriyet.edu.tr \\ ORCID: $\quad$ 0000-0002-6720-3684 \\ ** Araş. Gör., Recep Tayyip Erdoğan Üniversitesi, Rize/Türkiye \\ E-Posta: aysegulylmzr@gmail.com \\ ORCID: $\underline{0000-0002-1331-9243}$
}

\section{Öz}

Bu araştırmanın amacı eğitimde medya okuryazarlığı ile ilgili yayımlanan akademik çalışmaları bibliyometrik açıdan incelemektir. Araştırmada nitel araştırma desenlerinden durum çalışması kullanılmıştır. Çalışma sürecinde WoS veri tabanlarında "Media Literacy" anahtar kelimesi kullanılarak araştırma temalarında arama yapılmıştır. Arama kriteri olarak "doküman başlığı, özet, anahtar kelime" seçilmiştir. Araştırmaya 1970-2021 yılları arasında yayımlanan yayınlar dâhil edilmiştir. WoS 'ta eğitim araştırmaları kategorisinde yer alan 919 akademik çalışmaya ait bibliyometrik veri, çalışmanın veri setini oluşturmaktadır. Araştırmada ulaşılan sonuçlara göre; eğitimde medya okuryazarlığı ile ilgili yayımlanan akademik çalışmalar 2008 yılı sonrasında, ilerleyen yıllara paralel bir şekilde artmıştır. Eğitimde medya okuryazarlı̆̆ı alanında en sık yayın yapılan diller sırasıyla İngilizce, İspanyolca ve Rusça, en çok yapılan akademik çalışma ise makale, bildiri ve kitap bölümüdür. Huelva Üniversitesi, Cantabria Üniversitesi ve Pennsylvania İngiliz Milletler Topluluğu Yükseköğretim Sistemi en çok yayın yapan araştırmacıların bulunduğu kurumlardır. Türkiye'de ise Anadolu Üniversitesi eăitimde medya okuryazarlığıyla ilgili en çok yayın yapan yazarların çalıştı̆̆ı kurumdur. $A B D$ ve İspanya ise sırasıyla medya okuryazarlığı ile ilgili yayınların en çok yayımlandığı iki ülkedir. 2000 yılı sonrasında yayımlanan akademik yayınların atıf sayılarında, her geçen yıl artan bir durum söz konusudur. Medya okuryazarlı̆̆ı ile ilgili yapılan akademik yayınlarda en çok kullanılan anahtar kelimeler ise "medya okuryazarlı̆̆ı, medya eğitimi, eğitim ve dijital okuryazarlık" kavramlarıdır.

Anahtar Kelimeler: Ĕ̆itim, medya okuryazarlığı, bibiyometrik analiz, Web of Science. 


\title{
A Bibliometric Analysis of Studies on Media Literacy in Education
}

*

\begin{abstract}
The purpose of this study is to examine the published academic studies on media literacy in education from a bibliometric perspective. The study used the case study design, which is a qualitative research design. The keyword "Media Literacy" was searched in research topics in the Web of Science (WoS) database. "Document title", "abstract", and "keyword" were chosen as search criteria. Studies published between 1970 and 2021 were included in the analysis. The bibliometric data of 919 academic studies contained in WoS educational researchs category constitute the data set of the study. The study found that academic studies on media literacy in education increased especially as of 2008 and this trend continued in the following years. The most frequent languages of publication in the field of media literacy in education are English, Spanish and Russian, respectively, and the most frequent types of academic research are articles, papers, and book chapters. The University of Huelva, the University of Cantabria, and the Pennsylvania Commonwealth System of Higher Education are the affiliations with the highest number of publishing researchers. In Turkey, Anadolu University is the affiliation with the biggest number of authors publishing research on media literacy in education. The USA and Spain are the two countries where studies on media literacy in education are published the most, respectively. The number of citations of academic studies published after 2000 is increasing every passing year. The most frequently used keywords in academic studies on media literacy in education are the concepts of "media literacy", "media education", "education", "digital literacy" and "media".
\end{abstract}

Key Words: Education, media literacy, bibliometric analysis, Web of Science. 


\section{Giriş}

Çeşitli biçimlerde mesajlara ulaşma, analiz etme, değerlendirme ve iletme yeteneği (Aufderheıde ve Firestone, 1992, s.1) olarak tanımlanan medya okuryazarlığı, bizi çevreleyen karmaşık, sürekli değişen elektronik ortam ve iletişim dünyası içinde gerekli, kaçınılmaz ve gerçekçi bir tepkiyi temsil etmektedir. Gittikçe karmaşıklaşan bilgi ve eğlence ortamlarında, bireylerle çok algısal bir şekilde konuşan medya, bireylerin duygu, düşünce ve davranış şekillerini etkilemektedir (NAMLE, 2020). Bu etki ve mesaj yoğunluğu içerisinde güvenle yol alabilmek, medya mesajlarına ulaşmak ve bu mesajları doğru çözümleyebilmek için medya okuryazarlığ1 becerisine ihtiyaç duyulmaktadır (RTÜK, 2021). Bu ihtiyacın bir sonucu olarak 2000'li yıllardan sonra medya okuryazarlı̆̆ alanında yapılan akademik çalışmaların oranında artışlar görülmüştür.

Özellikle 2020 yılında bütün dünyayı saran küresel salgın, ortaya çıktığı ilk günden itibaren kişilerin evde kalma süresini oldukça arttırmış, bunun bir sonucu olarak televizyon izleme oranları büyük oranda yükselmiş ve internet tabanlı platformlara yönelimler artmıştır. Kişiler üzerinde medyanın etkisi arttıkça, medya okuryazarlığı eğitiminin ve medya okuryazarı olmanın önemi de artmaktadır. Bu önemin bir sonucu olarak medya okuryazarlığı konusunda yapılan akademik çalışmaların hacminde de bir artışın olacağı açıktır. Bu kapsamda medya okuryazarlığı ve eğitimi alanında çalışma yapacak olan araştırmacıların alandaki eğilimleri, konuları ve genel yapıyı bir bütün olarak görmeleri oldukça önemlidir.

Konuların ele alınış biçimi ve içeriği, makale yazma işinin önemli bir parçasıdır ve daima araştırmacılara rehberlik etmektedir. Bu açıdan makalelerdeki çalışma konularının yönelimlerini bilmek önemlidir. Çalışılan araştırmaların bu yönünü inceleyen çalışmalar bibliyometrik çalışmalardır (Sönmez, 2020, s.216). Bibliyometrik analizler, bilimsel yayınların sayısal analizine odaklanan (Wilsdon ve diğerleri, 2015, s.5) ve yayınların performansını değerlendirmek, yazarları ve kurumları takip etmek için güvenilir ve bilgilendirici analizlerdir (Özsoy ve Demir, 2018, s.2340). Bu analizler sayesinde; yazar, konu, atıf yapılan yazar, atıf yapılan kaynaklar gibi verilerin istatistiksel olarak incelenmesi ve elde edilen 
istatistiksel sonuçlar ışığında belirlenen alana ait genel yapının ortaya konması mümkün olmaktadır (Bozkurt ve Çetin, 2015, s.232).

Belirli bir alan hakkında bir dizi yayın toplamak bibliyometrik çalışma yürütmenin ilk adımını oluşturmaktadır. Bu kapsamda araştırmaya dâhil edilen çalışmaların araştırma alanını gerçekten temsil etmesi ve değerlendirilecek veri türünün başlangıçta tanımlanması önemlidir. Veri türü belirlendikten sonra çalışmanın amacına göre bibliyometrik göstergeler (yazarlar, araştırma grupları, dergiler, ülkeler vb) özenle seçilmelidir (Andres, 2009, s.9). Seçilen araştırmalar ve içerikleri araştırmanın analizinin temelini oluşturduğu için bibliyografik arama, sürecin önemli bir parçasını oluşturmaktadır. Bu araştırmada, eğitimde medya okuryazarlığı alanındaki çalışmaların yayın yılı, dili, türü, yayını hazırlayan yazarların kurumları, yayınlandıkları kaynaklar, ülkeler, atıf analizi ve yaymlardaki anahtar kelimeler bibliyometrik gösterge olarak belirlenmiştir.

Bibliyometrik araştırmalarda analiz edilecek çalışmalar, belirli bir çalışma alanıyla ilgili yayınları bir araya getiren veri tabanlarından toplanabileceği gibi, multidisipliner bir veri tabanından da toplanabilir (Andres, 2009, s.10). Bu araştırmada analize dâhil edilen yayınlara ilişkin bilgiler multidisipliner veri tabanlarından biri olan Web of Science'dan (WoS) alınmıştır. Web of Science, bilimsel sonuçları indeksleyen ve bunları Sosyal Bilimler Atıf Dizini (SSCI) dâhil olmak üzere birkaç alt veri tabanında sinıflandıran bir atıf veri tabanıdır (Ivanovića ve Hob, 2019, s.277).

Eğitim bilimleri alanında yapılan çalışmaların hacminde özellikle son yıllarda bir artış görülmektedir. 2000'li yıllardan sonra medya okuryazarlığı ve eğitimi alanında da kısa sürede birçok çalışma yapılmıştır. Bu artan araştırma hacmiyle birlikte bibliyometrik araştırmaların medya okuryazarlığı alanında da yapılmasının bir ihtiyaç olduğu düşünülmektedir. Çünkü araştırmacılar, bu çalışmalar sayesinde çalışacakları alanın genel bir tablosunu görerek nerede geliştirilmeye ve çalışılmaya açık bir konunun olabileceğini çok daha rahat bir şekilde görebileceklerdir.

Literatür incelendiğinde, Türkiye'de medya okuryazarlığı eğitimi alanında yapılmış farklı içerik analizi çalışmalarına rastlanmıştır. Altun (2014) medya okuryazarlığına yönelik bir bibliyografya çalışması yapmış 
ve araştırmasında medya okuryazarlığı eğitimi alanında hazırlanmış 233 çalışmanın tam künyesine yer vermiştir. Ayrıca yayınları; yıl, yayın türü, içerik açısından analiz ederek Türkiye'deki medya okuryazarlığı eğitimi çalışmalarının genel bir fotoğrafını ortaya koymuştur. Kıncal ve Korkmaz (2015) Türkiye'de medya okuryazarlığı konusunda çalışılan 66 makaleyi; yılı, konu alanı, yöntemi, veri toplama aracı, örneklemi, veri analiz yöntemi ve boyutlarını kapsayacak şekilde incelemişlerdir. Ardıç, (2016) Türkiye, ABD ve Kanada'da medya okuryazarlığı alanında çalışılan lisansüstü çalışmaları karşılaştırmalı olarak incelemiş, her üç ülkede çalışılan tezlerin, araştırma yaklaşımları, örneklemleri, eğitim kademeleri ve yapıldıkları tarih açısından dağılımlarını belirlemiştir. Maden, Maden ve Banaz (2017) ve Erdem (2018) ise medya okuryazarlığ1 ile ilgili lisansüstü tezlere yönelik bir içerik analizi yapmışlardır. Kardaş ve Yıldırım (2017) medya okuryazarlığı üzerine yapılan çalışmalara ilişkin bir kaynakça sunmuş ve araştırmaların yıllara göre dağılımları, türleri ve araştırmalarda kullanılan bilimsel araştırma yöntemleri hakkında bilgiler vermişlerdir. Aydemir ve Erdamar (2018) ise medya okuryazarlığı eğitimi alanındaki çalışmaların tematik, metodolojik ve istatistiksel yönelimlerinin dağılımlarını belirleyen bir içerik analizi yapmışlar ve inceledikleri araştırmaların yıllara, konu alanlarına, araştırma yöntem ve modellerine, örneklem yöntemlerine ve gruplarına, veri toplama araçlarına, veri analiz tekniklerine ve yapılan önerilere göre dağılımlarına bakmışlardır.

Yapılan bu çalışmalar incelendiğinde, çalışmaların içerik analizi şeklinde yürütüldüğ̈̈ ve sadece yurtiçinde ki çalışmalara odaklanıldığı görülmüştür. Bibliyometrik analiz, içerik analizi ya da doküman analizine kıyasla bir alandaki çalışma dinamiklerini, değişimleri, araştırma yenilikleri ve eğilimlerini göstermesi yönüyle daha işlevseldir (Karagöz ve Şeref, 2019, s.135). Eğitimde medya okuryazarlı̆̆ı alanında yapılan çalışmaların bibliyometrik analizini ortaya koyan kapsamlı bir araştırmaya literatürde rastlanmamıştır. Eğitimde medya okuryazarlığ alanının WoS'taki etkinliğini bibliyometrik göstergeler açısından ele alan bu araştırma, alanın uluslararası görünümünü ve Türkiye'nin bu alandaki yerini ve durumunu ortaya koyacaktır. Bu çalışmanın alandaki eksikliği gidereceği ve alanla ilgi çalışma yapmak isteyenlere yardımcı olacağ düşünülmektedir. 
Bu kapsamda, araştırmanın amacı 1970-2021 yılları arasında eğitimde medya okuryazarlığı alanında yayınlanan ve Web of Science (WoS) veri tabanında indekslenen yayınları bibliyometrik olarak analiz etmektir. Araştırma, bütüncül bir yoruma ulaşılabilmek amaciyla 1970-2021 yılları arasındaki 51 yıllık zaman dilimini kapsayacak şekilde gerçekleştirilmiştir. Araştırmanın amacı doğrultusunda aşağıdaki sorulara cevap aranmıştır.

- Eğitimde medya okuryazarlığı alanında yayımlanan akademik çalışmaların yıllara göre sayısal dağılımı nasıldır?

- Eğitimde medya okuryazarlığı alanında yayımlanan akademik çalışmaların hazırlandıkları dillere göre dağılımları nasıldır?

- Eğitimde medya okuryazarlığı alanında yayımlanan akademik çalışmaların yayın türlerine göre dağılımları nasıldır?

- Eğitimde medya okuryazarlığı alanında yayımlanan akademik çalışmaların, yazarlarının çalıştığı kurumlara göre dağılımları nasıldır?

- Eğitimde medya okuryazarlığı alanında yayımlanan akademik çalışmaların yayımlandığı kaynaklara göre dağılımları nasıldır?

- Eğitimde medya okuryazarlığı alanında yayımlanan akademik çalışmaların yayımlandığı ülkelere göre dağılımları nasıldır?

- Eğitimde medya okuryazarlığı alanında yayımlanan akademik çalışmaların yıllara göre atıf sayıları nedir?

- Eğitimde medya okuryazarlığı alanında yayımlanan akademik çalışmalarda en sık kullanılan anahtar kelimeler nelerdir?

\section{Yöntem}

\section{Araştırma Deseni}

Çalışma nitel araştırma desenlerinden durum çalışmasıyla gerçekleştirilmiştir. Durum çalışması sınırlı bir sistemin nasıl işlediği ya da çalıştı̆̆ 1 hakkında sistematik olarak bilgi toplamak için birden fazla veri toplama biçimini kullanan, bu sınırlı sistemin derinlemesine araştırılmasına olanak veren metodolojik bir yaklaşımdır (Chmiliar, 2010, s.582). Johnson ve Christensen (2014, s.395) durum çalışmasını bir ya da daha fazla duruma ilişkin detaylı bir açılama ve analiz ortaya koyan bir 
araştırma türü olarak tanımlamaktadırlar. $\mathrm{Bu}$ araştırmada eğitimde medya okuryazarlığıyla ilgili akademik araştırmalar bibliyometrik parametreler açısından incelenip mevcut durum ortaya koyulmak istendiği için durum çalışması deseni benimsenmiştir.

\section{Veri toplama Aracı}

$\mathrm{Bu}$ çalışmanın veri toplama aşamasında Web of Science (WoS) veritabanları kullanılmıştır. "Thomson Reuters Institute of Scientific Information (ISI)" ürünü olan Web of Science, 1960'larda Eugene Garfield tarafından oluşturulan Science Citation Index'ten doğmuştur (Chadegani, ve diğerleri, 2013, s.19). Günümüzde Web of Science, 37.000'in üzerinde dergiyi ve 171 milyondan fazla kaydı içermekte ve dergilerden, konferanslardan, raporlardan, kitaplardan ve kitap serilerinden toplanan farklı bilgileri içeren farklı atıf veri tabanlarından (SCI, SSCI, SCIExpanded, AHCI, ESCI, CPCI-S, CPCI-SSH, BKCI-S, BKCI-SSH) çeşitli veriler içermektedir. Çalışma sürecinde Web of Knowledge Web sayfasında tüm WoS veri tabanlarında "Media Literacy" anahtar kelimesi kullanılarak araştırma başlıklarında arama yapılmıştır. Arama kriteri olarak "doküman başlığı, özet, anahtar kelime" seçilmiştir. Çalı̧̧ma bütüncül bir yoruma ulaşılabilmek amacıyla 1970-2021 yılları arasındaki 51 yıllık zaman dilimini kapsayacak şekilde gerçekleştirilmiştir. Arama sonucunda ulaşılan 2.366 sonuçtan "Eğitim/Eğitim Araştırmaları" kategorisinde yer alan 919 akademik çalışmaya ait bibliyometrik veri çalışmanın veri seti olarak kullanılmıştır.

\section{Verilerin Analizi}

Çalışmada veri analizi tekniği olarak bibliyometrik analiz kullanılmıştır. İstatistiksel bibliyografya ilk olarak 1922' de Cambridge Üniversitesi'nden E. Wyndham Hulme tarafından kullanılmış olsa da bibliyometrik analiz ilk kez Pritchard tarafından kullanılmıştır. Pritchard, bibliyometrik analizi matematiğin ve istatistiksel yöntemlerin kitaplara ve diğer bilimsel iletişim araçlarına uygulanması olarak ifade etmiştir (Pritchard, 1969).

Çalışmada 1970'den 2021'e kadar olan dönemde medya okuryazarlı̆̆1 ile ilgili olarak yayınlanmış olan toplam 919 yayın, bibliyometrik 
göstergeler açısından incelenerek kategorize edilmiştir. Kategorize edilen verilere ilişkin yüzde ve frekanslar hesaplanmıştır.

Çalışma kapsamında incelenen akademik yayınların araştırma konuları ve yönelimleri yayınlardaki anahtar kelimeler üzerinden görsel olarak haritalandırılmıştır. Bu doğrultuda WordArt çevrimiçi kelime bulutu yazılımı tercih edilmiştir.

Medya okuryazarlığı ile ilgili 919 akademik çalışmanın anahtar kelimelerinin sosyal ağ analizi bibliyometrik analiz araçlarından VOSviewer (Version 1.6.16) paket programı aracılığıla görselleştirilmiştir.

VOSviewer, ağ verilerine dayalı haritalar oluşturmak ve bu haritaları görselleştirerek keşfetmek için kullanılan bir yazılım aracıdır. VOSviewer'ın işlevleri şu şekilde özetlenebilir:

- A $\breve{g}$ verilerine dayalı haritalar oluşturma: Bilimsel yayınlar, bilimsel dergiler, araştırmacılar, araştırma kuruluşları, ülkeler, anahtar kelimeler ya da terimlerden oluşan ağlar oluşturmak için kullanılabilir. Bu ağlardaki öğeler ortak yazarlık, birlikte bulunma, alıntı, bibliyografik eşleştirme veya ortak alıntı bağlantılarıyla birbirine bağlanabilir.

- Haritaları görselleştirme ve keşfetme: VOSviewer, bir haritanın üç farklı şekilde görselleştirmesini sağlar: A ğ görselleştirme, katman görselleştirme ve yoğunluk görselleştirme (Van Eck ve Waltman, 2013, s.3).

\section{Bulgular}

Araştırma sorusuna yönelik bulgular: Yayın Sayısı: WoS'ta eğitim araştırmaları kategorisinde medya okuryazarlı̆̆ akademik çalışmaların yıl bazında dağılımı Grafik 1'de yer almaktadır.

Grafik 1'de yer alan verilere göre medya okuryazarlığıyla ilgili olarak en fazla yayın yapılan yıllar 2018 ( $\mathrm{f}=108)$ ve 2017 ( $\mathrm{f}=104)$ olmuştur. Daha sonra sirasiyla 2020 ( $\mathrm{f}=98), 2016(\mathrm{f}=96)$ ve 2015 ( $\mathrm{f}=79$ ) yılları gelmektedir. Grafik bir bütün olarak değerlendirildiğinde 2008 yılı ve sonrasında medya okuryazarlığı ile ilgili yayımlanan akademik çalışmaların ilerleyen yıllara paralel olarak artış gösterdiği söylenebilir. Bir istisna olarak 2021 
yılına ait yayın sayısının düşük görülme sebebi ise çalışmanın 2021 yılı Nisan ayında yapılmasıyla ilişkilidir.

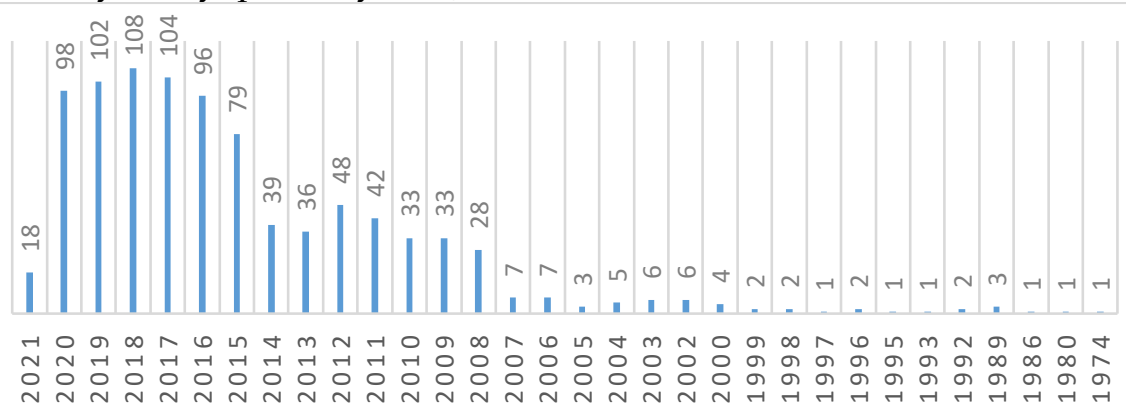

Grafik 1. Eğitimde medya okuryazarlığı ile ilgili araştırmalarn yıllara göre sayısal dağılımı (WoS, Nisan, 2021)

\section{Araştırma Sorusuna Yönelik Bulgular: Yayın Dili}

WoS'ta eğitim araştırmaları kategorisinde medya okuryazarlığı ile ilgili yayımlanan akademik çalışmaların hazırlandıkları dillere dağılımı Tablo 1 'de yer almaktadır.

Tablo 1. Eğitimde medya okuryazarlı̆̆ı ile ilgili araştırmaların hazırlandıkları dillere göre dağılımı (WoS, Nisan, 2021)

\begin{tabular}{lll}
\hline Yayın Dili & f & $\mathbf{\%}$ \\
\hline İngilizce & 765 & 83,24 \\
İspanyolca & 126 & 13,71 \\
Rusça & 6 & 0,65 \\
Almanca & 5 & 0,54 \\
Portekizce & 5 & 0,54 \\
Türkçe & 5 & 0,54 \\
Çince & 3 & 0,32 \\
Slovence & 2 & 0,21 \\
Bulgarca & 1 & 0,10 \\
Estçe & 1 & 0,10 \\
Toplam & 919 & 100 \\
\hline
\end{tabular}

Tablo 1'de yer alan veriler incelendiğinde medya okuryazarlığıyla ilgili olarak en sık yayın yapılan dillerin başında İngilizce ( $\mathrm{f}=765$ ) ve İspanyolca $(\mathrm{f}=126)$ gelmektedir. En sık yayın yapılan dillerin başında gelen İngilizce dilinde yayın sayısının diğer dillere nispeten bu kadar fazla olmasının 
sebebi, İngilizcenin bir bilim dili olarak yaygın kullanımı ve WoS veritabanlarında indekslenen dergilerin yayın dili tercihlerinin olabileceği düşünülebilir.

\section{Araştırma Sorusuna Yönelik Bulgular: Yayın Türü}

WoS'ta eğitim araştırmaları kategorisinde medya okuryazarlığı ile ilgili yayımlanan akademik çalışmaların yayın türlerine göre dağılımı Grafik 2 ' de yer almaktadir.

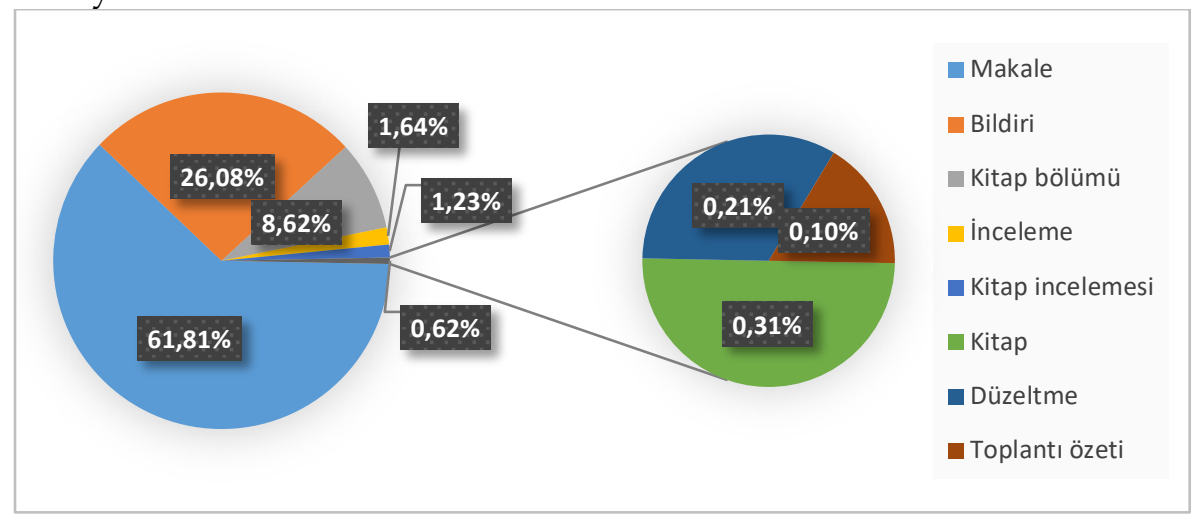

Grafik 2. Yayın türlerine göre eğitimde medya okuryazarlı̆̆ ile ilgili yayın sayılarının dağılımı (WoS, Nisan, 2021)

Grafik 2'de yer alan veriler incelendiğinde eğitimde medya okuryazarlığıyla ilgili olarak yayımlanan akademik çalışmaların büyük bir kısmını makalelerin $(\% 61,81)$ oluşturduğu sonrasında en sık yayın yapılan diğer türlerin ise sırasılyla bildiri $(\% 26,08)$, kitap bölümü $(\% 8,62)$ ve inceleme $(\% 0,62)$ olduğu görülmektedir.

\section{Araştırma Sorusuna Yönelik Bulgular: Yazarların Kurumları}

WoS'ta eğitim araştırmaları kategorisinde medya okuryazarlığı ile ilgili yayımlanan akademik çalışmaların yazarlarının çalıştığı kurumlara göre dağılımı Tablo 2'de yer almaktadır. Bu kategoride yer alan kurum sayısının fazla $(\mathrm{n}=866)$ olması nedeniyle tabloda yalnızca yayın sayısına göre ilk 10 kuruma yer verilmiştir. 
Tablo 2. Ĕ̆itimde medya okuryazarliğı ile ilgili yayın yapan yazarların kurumlarıilk 10 kurum (WoS, Nisan, 2021)

\begin{tabular}{lll}
\hline Kurumlar & $\mathbf{f}$ & $\mathbf{\%}$ \\
\hline Huelva Üniversitesi & 23 & 2,50 \\
Cantabria Üniversitesi & 18 & 1,96 \\
Pennsylvania İngiliz Milletler Topluluğu Yükseköğretim Sistemi PCSHE & 15 & 1,63 \\
Ukrayna Eğitim Bilimleri Bakanlığı & 13 & 1,41 \\
Kuzey Carolina Üniversitesi & 13 & 1,41 \\
Valladolid Üniversitesi & 12 & 1,30 \\
Georgia Üniversite Sistemi & 12 & 1,30 \\
Nanyang Teknoloji Üniversitesi & 11 & 1,20 \\
Nanyang Teknoloji Üniversitesi Ulusal Eğitim Enstitüsü (NIE) & 11 & 1,20 \\
Ulusal Eğitim Enstitüsü (NIE) & 11 & 1,20 \\
\hline
\end{tabular}

Tablo 2'de yer alan veriler incelendiğinde eğitimde medya okuryazarlı̆̆ıyla ilgili olarak yayın yapan yazarların çalıştığı ya da desteklendiği kurumların başında Huelva Üniversitesi - İspanya ( $\mathrm{f}=23)$, Cantabria Üniversitesi - İspanya ( $\mathrm{f}=18$ ) ve bünyesinde birçok üniversiteyi barındıran Pennsylvania İngiliz Milletler Topluluğu Yükseköğretim Sistemi - ABD ( $\mathrm{f}=15)$ yer almaktadır. Bu kategoride listelenen 34 Türkiye kurumundan ilk 10'u ve bu kurumların 866 kurum arasındaki sıralamaları tablo 3'te verilmiştir.

Tablo 3. Eğitimde medya okuryazarlı̆̆ı ile ilgili yayın yapan yazarlarn kurumlarıTürkiye ilk 10 kurum (WoS, Nisan, 2021)

\begin{tabular}{lll}
\hline Kurumlar & f & \% \\
\hline 56. Anadolu Üniversitesi & 4 & 0,43 \\
83. Afyon Kocatepe Üniversitesi & 3 & 0,32 \\
88. Çanakkale On Sekiz Mart Üniversitesi & 3 & 0,32 \\
101. Milli Eğitim Bakanlığ1 & 3 & 0,32 \\
104. On Dokuz Mayis Üniversitesi & 3 & 0,32 \\
157. Çukurova Üniversitesi & 2 & 0,21 \\
165. Hacettepe Üniversitesi & 2 & 0,21 \\
278. Adnan Menderes Üniversitesi & 1 & 0,10 \\
279. Ağrı İbrahim Çeçen Üniversitesi & 1 & 0,10 \\
281. Akdeniz Üniversitesi & 1 & 0,10 \\
\hline
\end{tabular}

Tablo 3'te yer alan veriler incelendiğinde ülkemizde medya okuryazarlığıyla ilgili olarak yayın yapan yazarların çalıştığı ya da desteklendiği kurumların başında Anadolu Üniversitesi (f=4), Afyon Kocatepe Üniversitesi ( $\mathrm{f}=3$ ), Çanakkale On Sekiz Mart Üniversitesi ( $\mathrm{f}=3$ ), 
MEB ( $\mathrm{f}=3$ ) ve On Dokuz Mayıs Üniversitesi'nin ( $\mathrm{f}=3$ ) geldiği görülmektedir.

\section{Araştırma Sorusuna Yönelik Bulgular: Kaynaklar}

WoS'ta eğitim araştırmaları kategorisinde medya okuryazarlı̆̆ı ile ilgili yayımlanan akademik çalışmaların yayımlandığı kaynaklara göre dağılımı Tablo 4'te yer almaktadır. Bu kategoride yer alan kaynak sayısının fazla $(\mathrm{n}=465)$ olması nedeniyle tabloda yalnızca yayın sayısına göre ilk 10 kaynağa yer verilmiştir.

Tablo 4. Eğitimde medya okuryazarlığı ile ilgili yapılan yayınların yayımlandığı kaynaklar- Illk 10 Kaynak (WoS, Nisan, 2021)

\begin{tabular}{lll}
\hline Dergi & f & \% \\
\hline Comunicar & 99 & 10,77 \\
Inted Proceedings & 41 & 4,46 \\
Edulearn Proceedings & 35 & 3,80 \\
Reading Research Quarterly & 26 & 2,82 \\
Iceri Proceedings & 23 & 2,50 \\
Journal Of Adolescent Adult Literacy & 21 & 2,28 \\
Learning Media and Technology & 19 & 2,06 \\
Procedia Social And Behavioral Sciences $\quad$ Education & 19 & 2,06 \\
International Handbook Of Media Literacy $\quad 15$ & 1,63 \\
Advances in Social Science Education and Humanities Research & 14 & 1,52 \\
\hline
\end{tabular}

Tablo 4'te yer alan veriler incelendiğinde medya okuryazarlığıyla ilgili olarak yayın yapılan kaynakların başında Comunicar ( $\mathrm{f}=99)$, Inted Proceedings $(\mathrm{f}=41)$, Edulearn Proceedings $(\mathrm{f}=35)$ ve Reading Research Quarterly'nin ( $\mathrm{f}=26)$ geldiği görülmektedir. Dergiler arasında yayın sayısına göre ortaya çıkan bu sıralamanın dergilerin yayınlandığı ülkeler, ülkelerde konunun çalışılma yoğunluğu ile ilişkili olduğu söylenebilir. Aynı şekilde kurumlara ilişkin bulgular da bu kanaati destekler niteliktedir.

\section{Araştırma Sorusuna Yönelik Bulgular: Ülkeler}

WoS'ta eğitim araştırmaları kategorisinde medya okuryazarlığı ile ilgili yayımlanan akademik çalışmaların yayımlandığı ülkelere göre dağılımı 
Tablo 5'te yer almaktadır. Bu kategoride yer alan kaynak sayısının fazla $(n=75)$ olması nedeniyle tabloda yalnızca yayın sayısına göre ilk 10 ülkeye yer verilmiştir.

Tablo 5. Eğitimde medya okuryazarlığı ile ilgili yapılan yayınların yayımlandığı ülkeler-Illk 10 ülke (WoS, Nisan, 2021)

\begin{tabular}{lll}
\hline Ülke & f & $\mathbf{\%}$ \\
\hline Amerika Birleşik Devletleri & 265 & 28,83 \\
İspanya & 153 & 16,64 \\
Çin Halk Cumhuriyeti & 48 & 5,22 \\
İngiltere & 36 & 3,91 \\
Almanya & 36 & 3,91 \\
Türkiye & 35 & 3,80 \\
Kanada & 31 & 3,37 \\
Portekiz & 31 & 3,37 \\
Avustralya & 25 & 2,72 \\
Rusya & 22 & 2,39 \\
\hline
\end{tabular}

Tablo 5'te yer alan veriler incelendiğinde medya okuryazarlığıly ilgili olarak yayın yapılan ülkelerin başında ABD ( $f=265)$, İspanya $(f=153)$ ve Çin Halk Cumhuriyeti'nin ( $\mathrm{f}=48$ ) geldiği görülmektedir.

Eğitimde medya okuryazarlığ 1 ile ilgili yapılan yayınların ortak yazarlık analizinde ülkeler ve kurumlar arası iş birliği Şekil 1'de gösterilmiştir. Her bir analizdeki dügümler ülkeleri ve kurumları temsil ederken aralarındaki dügüm boyutları yayınlanan makaleleri, mesafe ve bağlantı çizgilerinin kalınlığı ise iş birliği derecesini yansıtmaktadır. Programda ülkelerden alıntılanan makale sayısı minimum 3, seçildiğinde 75 ülkenin 51'i eşik değerini karşılamaktadır. Bu ülkeler 9 kümeye ayrılmakta ve aralarında 79 bağlantı çizgisi bulunmaktadır. Bağlantı sayısına göre İspanya en yüksek (42 bağlantı) sayıya sahiptir. İspanya'yı ABD (40 bağlantı), Çin (11 bağlantı) ve İngiltere (10 bağlantı) takip etmektedir. 


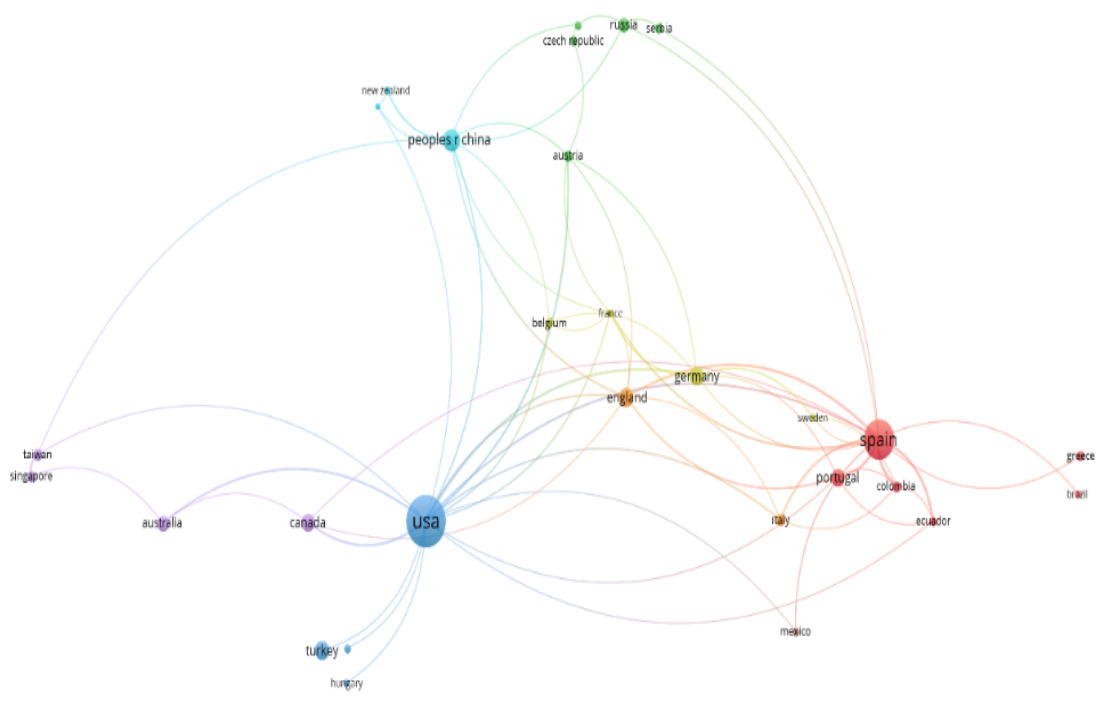

A vosviewer

Şekil 1. Eğitimde medya okuryazarlı̆̆ı ile ilgili akademik yayınların ortak yazarlık analizinde ülke ve kurum iş birlikleri (WoS, Nisan, 2021)

\section{Araştırma Sorusuna Yönelik Bulgular: Atıf Analizi}

WoS’ta eğitim araştırmaları kategorisinde medya okuryazarlığı ile ilgili yayımlanan akademik yayınların yıllara göre atıf sayıları Grafik 3'te yer Grafik 3'te yer alan veriler incelendiğinde eğitimde medya okuryazarlığı ile ilgili yayımlanan akademik yayınların 1991 yılına kadar kayıtlı bir atıf bilgisi bulunmazken 1991 - 2000 yılları arasında atıfların düşük oranda seyrettiği, 2000 yılı sonrasında ise her geçen yıl artan bir oranda atıf sayısının arttığı görülmektedir. Atıf sayısındaki bu artış medya kullanımın artmasıyla medya okuryazarlığının öneminin artması ve buna paralel olarak medya okuryazarlığı ile ilgili yapılan akademik çalışmaların sayısının artmasıyla ilişkilendirilebilir. 


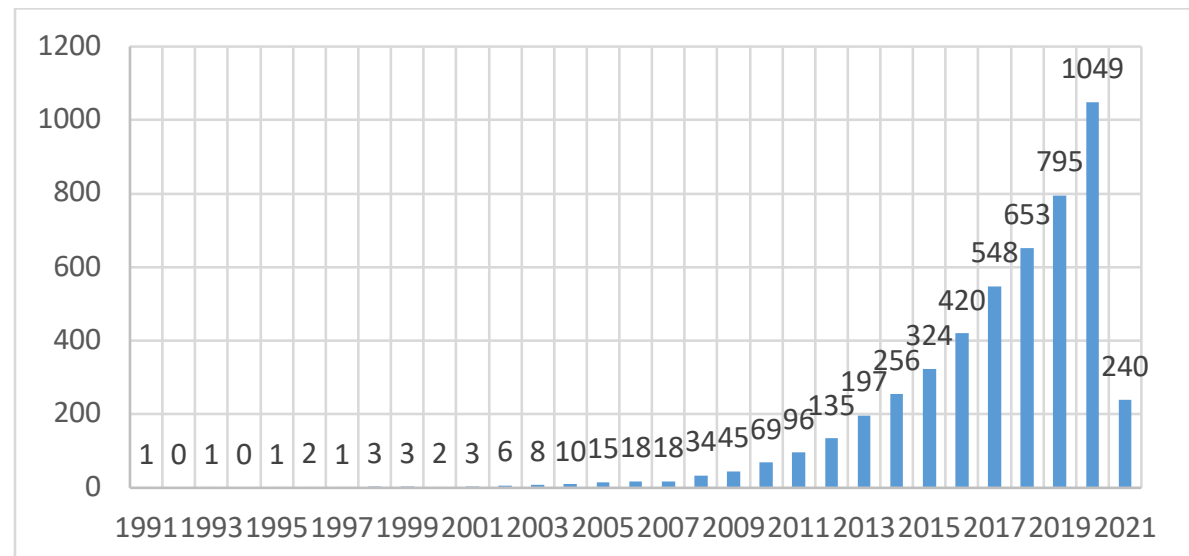

Grafik 3. Eğitimde medya okuryazarlı̆̆ı ile ilgili yayınların yıllara göre atıf sayıları (WoS, Nisan, 2021)

\section{Araştırma sorusuna yönelik bulgular: Anahtar Kelimeler}

Eğitim araştırmalarında medya okuryazarlığı ile ilgili akademik yayınlarda kullanılan anahtar kelimelerle ilgili sıklığı belirten veriler aşağıdaki kelime bulutu görselinde sunulmuştur.

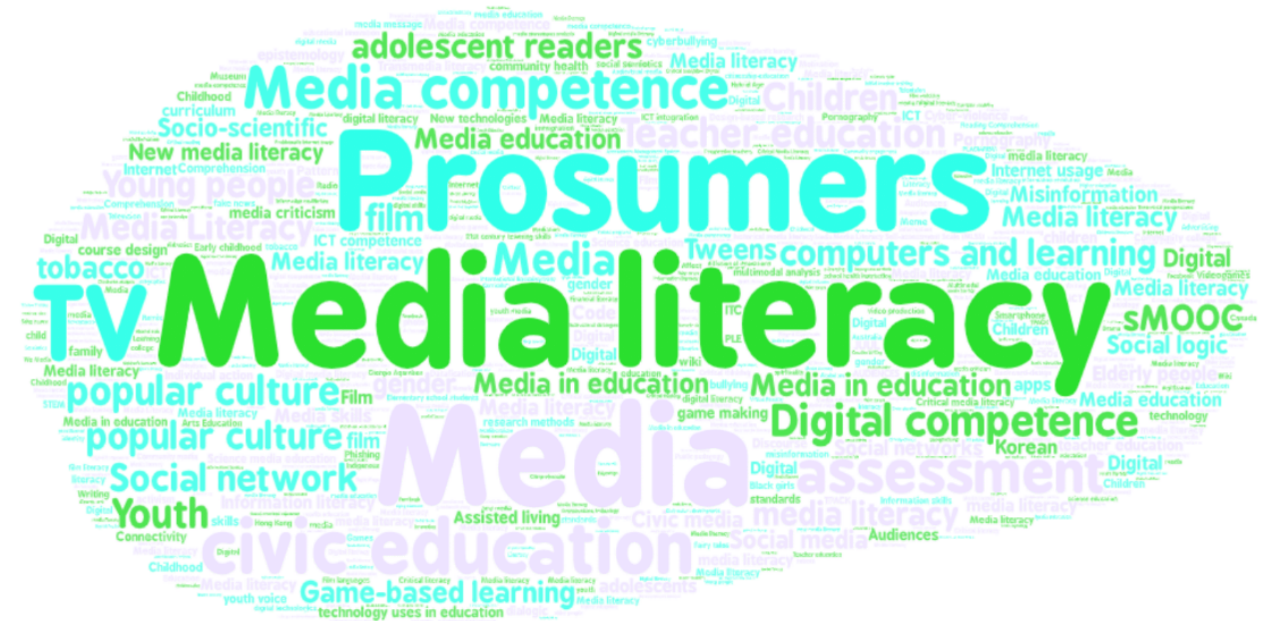

Şekil 2. Eğitimde medya okuryazarlı̆̆ı ile ilgili araştırmaların anahtar kelime sıkliğı (WoS, Nisan, 2021) 
Şekil 2.'de yer alan anahtar kelimeler incelendiğinde medya okuryazarlığı ile ilgili yapılan akademik yayınlarda en çok medya, medya okuryazarlığı, profesyonel tüketici, vatandaş eğitimi, medya yeterliliği, dijital yeterlilik, eğitimde medya, ergen okuyucular, sosyal ağ, popüler kültür, bilgisayar ve öğrenme gibi kavramların kullanıldı̆̆ görülmektedir.

Medya okuryazarlığı ile ilgili genel araştırma alanları ve bu alanlar arasındaki ilişkilerin sosyal ağ Şekil 3.'te gösterilmiştir.

Şekil 3 incelendiğinde anahtar kelime ağı grafiğindeki kümelenme analizine göre medya okuryazarlığı ile ilgili akademik yayınların 6 küme altında gruplandığı anlaşılmaktadır. Bu kümelerde yer alan anahtar kelimelerden en sık kullanılanlar medya okuryazarlığ1 $(\mathfrak{f}=386)$, medya eğitimi ( $\mathrm{f}=104)$, eğitim ( $\mathrm{f}=39$ ), dijital okuryazarlık ( $\mathrm{f}=38)$, medya ( $\mathrm{f}=37$ ) şeklindedir. Anahtar kelimelerden bağlantı gücü (bg) en yüksek olanlar medya okuryazarlığ $(b g=794)$, dijital (bg=248), medya eğitimi (bg=223), ergenlik (bg=149), yeni okuryazarlıklar (bg=123), dijital okuryazarlık (bg=112), sosyo-kültürel ( $b g=106)$, teorik perspektifler ( $b g=104)$, yöntemler ve materyaller $(b g=97)$, öğretim stratejileri $(b g=97)$ şeklinde sıralanmaktadır. Bu bağlantı ögeleri ile bağlanan kümeler birbirleriyle ilişkili kümelerin bağlantı odaklarıdır.

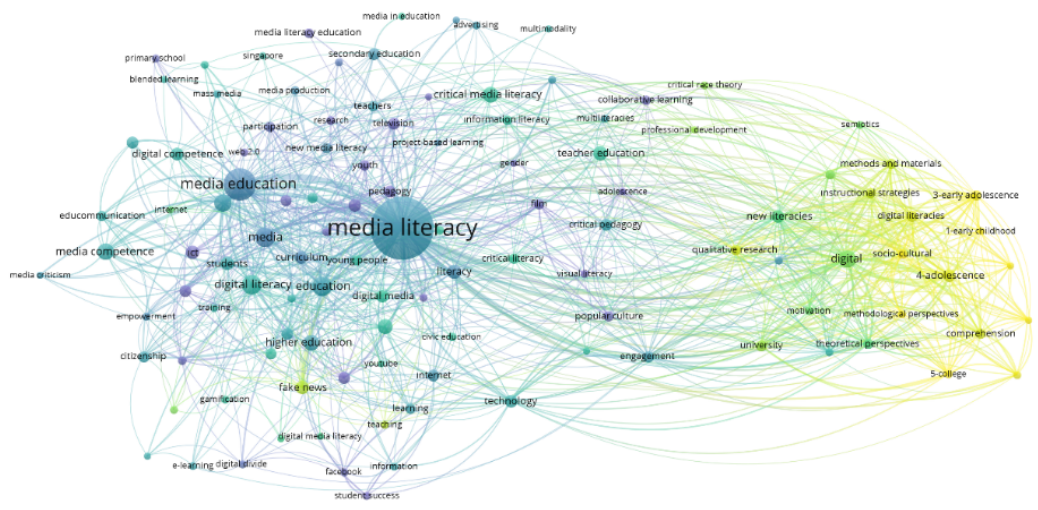

As vosviewe

Şekil 3. Anahtar kelimelerin sosyal ağ analizi (Daire büyüklïğ̈̈ en çok ele alınan konuyu, sarn alanlar ise güncel konularn göstermektedir.) 


\section{Sonuç ve Tartışma}

Medya okuryazarlığı eğitimi alanı, özellikle 2000'li yıllardan sonra ülkemizde akademik ilginin giderek arttığı bir disiplin haline gelmiştir (Altun, 2014, s.5). Akademik ilginin getirdiği sonuçlardan biri bu alanda yapılan çalışmaların sayısında olan artıştır. Dünyada olduğu gibi ülkemizde de her geçen gün medya okuryazarlığı alanında yapılan yayın sayısı artmaktadır. Ancak literatüre bakıldığında medya okuryazarlığı alanındaki yayınların bibliyometrik analizine yönelik yapılan bir çalışmaya rastlanmamıştır. Bu çalışma özellikle medya okuryazarlı̆̆ 1 alanında yeni çalışmalar yapacak olan araştırmacılara, alandaki çalışmaların yayın yılı, dili, türü, yayınlandıkları kaynaklar, ülkeler, yayını hazırlayan yazarların çalıştıkları kurumlar, atıf analizi ve yayınlardaki anahtar kelimeler konusunda bibliyometrik bir gösterge sunacak, ülkemizin diğer ülkeler arasındaki yerinin gösterilmesine fırsat taniyacaktır.

$\mathrm{Bu}$ araştırmada 1970-2021 yılları arasında eğitimde medya okuryazarlığı alanında yapılan ve Web of Science (WoS) veri tabanında indekslenen yayınları bibliyometrik olarak analiz etmek amaçlanmıştır. Arama sonucunda ulaşılan 2.366 sonuçtan Eğitim/Eğitim Araştırmaları kategorisinde yer alan 919 akademik çalışma, araştırmanın veri setini oluşturmuştur. Özet olarak bu araştırmada eğitimde medya okuryazarlığ 1 alanının WoS'taki etkinliği incelenmiş ve bibliyometrik göstergeler açısından analiz edilmiştir.

Araştırmanın sonuçlarına göre, eğitim araştırmaları kategorisinde medya okuryazarlığı alanında yapılan çalışmaların yıl bazlı dağılımları incelendiğinde en fazla yayın yapılan yıllar, sırasıyla 2018 ve 2017 yıllarıdır. Yayın yapılan yıllar bir bütün olarak değerlendirildiğinde özellikle 2008 yılı ve sonrasında yayımlanan akademik çalışmalar, ilerleyen yıllara paralel olarak artış göstermiştir. Araştırmada bir istisna olarak 2021 yılına ait yayın sayılarının düşük olması, 2021 yılının ilk birkaç ayındaki yayın sayılarının dikkate alınması ile ilişkilidir. Literatüre bakıldığında araştırmanın sonucunu destekleyen farklı çalışmalara rastlanmıştır. Altun (2014:13), medya okuryazarlığı ile ilgili yayınlarda her geçen yıl artış eğilimi olduğunu söyleyerek, özellikle 2007 ve 2008 
yıllarında, yayınların önceki yıllara oranla hızla artış gösterdiğini belirtmiştir. Aydemir ve Erdamar (2018); Kardaş ve Yıldırım (2017); Kıncal ve Korkmaz (2015); Maden, Maden ve Banaz (2017)'nin yaptı̆̆1 araştırmalara bakıldığında özellikle 2008'li yıllardan sonra medya okuryazarlığı alanında yapılan çalışmaların sayısında artışların olduğu görülmektedir.

WoS'ta eğitim araştırmaları kategorisinde medya okuryazarlığı ile ilgili yayımlanan akademik çalışmaların hazırlandığı diller incelendiğinde, ilk sırada \%83 gibi büyük bir oranla İngilizce gelmektedir. İngilizceyi, İspanyolca ve Rusça takip etmektedir. Medya okuryazarlığ 1 alanında en sık yayın yapılan dillerin başında İngilizcenin yer almasının bir sebebi İngilizcenin bir bilim dili olarak yaygın kullanımı iken, diğer bir sebebi ise WoS veritabanlarında indekslenen dergilerin yayın dili tercihleridir. WoS veri tabanında Türkçe olarak yayımlanan çalışmaların sayısı ise sadece beş ile sınırlıdır. Türkçe, yayın dili sıralamasında Almanca ve Portekizce ile aynı sayıda yayın bulundurarak dördüncü sırayı paylaşmaktadır. Bu durumun sebebi olarak WoS veri tabanlarında indekslenen dergilerin yayın dili şartları gösterilebilir.

WoS'ta eğitim araştırmaları kategorisinde medya okuryazarlığı ile ilgili yayımlanan akademik çalışmaların yayın türleri incelendiğinde çalışmaların büyük bir kısmını makalelerin oluşturduğu sonrasında en sık yayın yapılan diğer türlerin ise sırasıyla bildiri, kitap bölümü ve inceleme olduğu görülmektedir. Literatürde bu sonucu destekleyen benzer bulgularla sonuçlanmış eğitim araştırmalarına da rastlanmıştır (Bozdoğan, 2020; Fernández, Lozano, ve Cuenca, 2020; Jimenez, Prieto ve Garcia, 2019; Karagöz ve Şeref, 2019; Özkaya, 2018; Samul, 2020; Sönmez, 2020; Sönmez ve Bozdoğan, 2020). Ayrıca medya okuryazarlığı alanında Altun'un (2014); Kardaş ve Yıldırım'ın (2017); Aydemir ve Erdamar'ın (2018) yaptığı araştırmanın sonuçları da bu sonucu destekler niteliktedir. Medya okuryazarlığına yönelik, Türkiye'deki yayınların kaynak türlerine göre dağılımları sırasıyla Altun'un (2014) çalışmasında makale, kaynak kitap ve bildiri; Kardaş ve Yıldırım'ın (2017) çalışmalarında makale, bildiri ve yüksek lisans tezi; Aydemir ve Erdamar'ın (2018) çalışmasında ise makale, lisansüstü tez ve tam metinli bildiri şeklindedir. Çalışmaların yayın türleri sıralamalarındaki bu farklılıkların sebebi çalışılan yılların farklı zamanları kapsamasından kaynaklanabilir. 
WoS'ta eğitim araştırmaları kategorisinde medya okuryazarlığı ile ilgili yayımlanan akademik çalışmaların yazarlarının çalıştığı kurumlara göre dağılımları incelendiğinde, bu kategoride yer alan kurum sayısının oldukça fazla olduğu görülmüştür. Bu sebeple bu çalışmada sadece ilk on kurum ismi yer almıştır. Medya okuryazarlığıyla ilgili yayın yapan yazarların çalıştığı ya da desteklendiği kurumların başında Huelva Üniversitesi (İspanya), Cantabria Üniversitesi (İspanya) ve bünyesinde birçok üniversiteyi barındıran Pennsylvania İngiliz Milletler Topluluğu Yükseköğretim Sistemi (ABD) yer almaktadır. Bu kategoride listelenen 34 Türkiye kurumundan ilk $10^{\prime} \mathrm{u}$ incelendiğinde ise ülkemizde medya okuryazarlığıyla ilgili yayın yapan yazarların çalıştığı ya da desteklendiği kurumların başında Anadolu Üniversitesi gelmektedir. Anadolu Üniversitesi'ni, Afyon Kocatepe Üniversitesi, Çanakkale On Sekiz Mart Üniversitesi, MEB ve On Dokuz Mayıs Üniversitesi eşit sayıda yayınla takip etmektedir. Erdem (2018) ise çalışmasında medya okuryazarlığı ile ilgili lisansüstü tezlerin Türkiye'de en fazla Çanakkale On Sekiz Mart Üniversitesinde tamamlandığı bulgusuna ulaşmıştır.

WoS'ta eğitim araştırmaları kategorisinde medya okuryazarlı̆̆ı ile ilgili yayımlanan akademik çalışmaların yayımlandığı kaynaklara göre dağılımları incelendiğinde, medya okuryazarlığıyla ilgili yayın yapılan kaynakların başında Comunicar, Inted Proceedings, Edulearn Proceedings ve Reading Research Quarterly'nin geldiği görülmektedir. Bu bulgu dergilerin yayınlandığı ülkelere ilişkin bulgularla karşılaştırıldığında bu sıralamanın ülkelerde konuya ilişkin yürütülen çalışmaların sayısıyla ilgili olduğu söylenebilir. Yine kurumlara ilişkin bulgular da bu kanaati destekler niteliktedir.

$\mathrm{ABD}, \mathrm{WoS}^{\prime}$ ta eğitim araştırmaları kategorisinde medya okuryazarlığı ile ilgili yayımlanan akademik çalışmaların yayımlandığı ülkelerin başında gelmektedir. İspanya ve Çin Halk Cumhuriyeti ise sırasıyla medya okuryazarlığı alanında $\mathrm{ABD}^{\prime}$ den sonra en fazla çalışma yayımlayan iki ülkedir. Türkiye bu sıralamada ilk on içerisinde yer almakta olup İngiltere ve Almanya'dan sadece bir yayın daha az yayımlayarak listenin beşinci sırasında bulunmaktadır. Literatürde birçok araştırmada ABD yayımlanan akademik çalışmalarda ilk sırada yer almıştır (Bozdoğan, 2020; Gümüş, Gençoğlu, ve Şahin, 2020; Julia ve diğerleri, 2020; Özkaya, 2018; Samul, 2020; Sönmez, 2020). 
WoS'ta eğitim araştırmaları kategorisinde medya okuryazarlığı ile ilgili yapılan yayınların ortak yazarlık analizinde ülkeler ve kurumlar arası iş birliği incelendiğinde en yüksek iş birliği derecesine İspanya'nın sahip olduğu görülmektedir. İspanya'nın ardından sırasıyla $A B D$, Çin ve İngiltere en yüksek iş birliğine sahip üç ülkedir. Farklı kurumlardaki araştırmacılar tarafından üretilen ortak çalışmalar, bilimsel iletişim dizgesine etkinlik kazandırmaktadır (Karagöz ve Şeref, 2019, s.225). Dolayısıyla medya okuryazarlığı alanında da bu iş birliğinin güçlendirilmesi önemlidir. Bu şekilde medya okuryazarlığı alanında gerçekleştirilen yayınlar hem WoS'ta görünürlük kazanabilir hem de daha fazla sayıda atıf alabilir.

WoS'ta eğitim araştırmaları kategorisinde medya okuryazarlığı ile ilgili yayımlanan akademik yayınların yıllara göre atıf sayıları incelendiğinde, 1991 yılına kadar kayıtlı bir atıf bilgisine rastlanmamıştır. Atıflar; yazarlar, araştırmacı grupları veya ülkeler arasında bir bağlantı olduğunu ortaya koymakla birlikte bir çalışmanın bilimsel bir topluluk üzerindeki etkisi hakkında da bilgi vermektedir (Andres, 2009, s.55). Bu ifadeden yola çıarak 1991 yılına kadar medya okuryazarlığı alanında yapılan yayınlarda yazarlar ve ülkeler arasındaki bağlantının ve etkinin zayıf olduğu söylenebilir. Bu zayıf etkinin bir sebebi o yıllar arasındaki yayın sayılarının az olması olabilecekken, diğer bir sebebi ise teknolojinin günümüzdeki kadar ilerlemiş ve etkin olmaması, bunun sonucu olarak da yayınlara ulaşmadaki zorluklar olabilir. 1991 - 2000 yılları arasında atıfların düşük oranda seyrettiği 2000 yılı sonrasında ise atıf sayısının her geçen yıl artarak devam ettiği görülmektedir. Atıf sayısındaki bu artış; medya kullanımının artmasıyla birlikte medya okuryazarlığı eğitimin öneminin artması ve buna paralel olarak da medya okuryazarlığı ile ilgili yapılan akademik çalışmaların sayısının artmasıyla açıklanabilir.

WoS'ta eğitim araştırmaları kategorisinde medya okuryazarlığı ile ilgili akademik yayınlarda kullanılan anahtar kelimeler incelendiğinde en çok "medya, medya okuryazarlığı, profesyonel tüketici, vatandaş eğitimi, medya yeterliliği, dijital yeterlilik, eğitimde medya, ergen okuyucular, sosyal ağ, popüler kültür, bilgisayar ve öğrenme" gibi kavramların kullanıldığ1 görülmektedir. Anahtar kelime ağı incelendiğinde ise kümelenme analizine göre medya okuryazarlığı ile ilgili akademik yayınların 6 küme altında gruplandığı anlaşılmaktadır. Bu kümelerde yer 
alan anahtar kelimelerden en sık kullanılanlar "medya okuryazarlığı, medya eğitimi, eğitim, dijital okuryazarlık ve medya" şeklindedir. Anahtar kelimelerden bağlantı gücü en yüksek olanlar "medya okuryazarlı̆̆ı, dijital, medya eğitimi, ergenlik, yeni okuryazarlıklar, dijital okuryazarlık, sosyo-kültürel, teorik perspektifler, yöntemler ve materyaller, öğretim stratejileri" şeklinde sıralanmaktadır. Bu bağlantı ögeleri ile bağlanan kümeler birbirleriyle ilişkili kümelerin bağlantı odaklarını oluşturmaktadır.

Bu araştırma ile 1970-2021 yılları arası WoS veri tabanında eğitim araştırmaları kategorisinde yer alan medya okuryazarlığı ile ilgili toplam 919 yayın incelenmiştir. Bu bağlamda çalışmanın sınırlılığı WoS verileri kapsamında var olan eğitimde medya okuryazarlığı araştırmalarıdır. Araştırmacılar WoS ve diğer veri tabanlarını kullanarak eğitim bilimlerinin diğer disiplinlerinde de benzer bibliyometrik analizler yapabilirler. 


\title{
EXTENDED ABSTRACT
}

\section{A Bibliometric Analysis of Studies on Media Literacy in Education}

\author{
* \\ Erkan Yeşiltaş- Ayşegül Yılmazer \\ Cumhuriyet University-Recep Tayyip Erdoğan University
}

For researchers who want to study in a particular field, it is important to know the trends of research subjects in their field. Studies examining this aspect of the published studies are called bibliometric analyses (Sönmez, 2020, p.216). These analyses allow making a statistical analysis of data such as author, subject, cited author, and cited sources and revealing the general structure of the specified field in light of the obtained statistical results (Bozkurt and Çetin, 2015, p.232).

This study aims to make a bibliometric analysis of the studies on media literacy in education published between 1970 and 2021 and indexed in the Web of Science (WoS) database. The study covered the 51-year period from 1970 to 2021 to reach a holistic interpretation. The bibliometric indicators adopted in the study are publication year, language, type, affiliation of author(s), source of publication, country of publication, citation analysis, and keywords. Information about the publications included in the analysis was taken from WoS, one of the multidisciplinary databases. WoS is a citation database that indexes scientific results and classifies them into several sub-databases, including the Social Sciences Citation Index (SSCI). (Ivanovića and Hob, 2019, p.277)

The literature review indicates that Altun (2014), Ardıç (2016), Aydemir and Erdamar (2018), Kardaş and Yıldırım (2017), Kıncal and Korkmaz (2015), and Maden, Maden, and Banaz (2017) conducted content analyses and focused only on domestic studies (i.e., studies in Turkey). Compared to content analysis or document analysis, bibliometric analysis is a more functional analysis in terms of showing the research dynamics, changes, research innovations, and trends in a field (Karagöz and Şeref, 2019, p.135). The literature contains no comprehensive study revealing the 
bibliometric analysis of the studies conducted in the field on media literacy in education.

The study employed the case study design, which is a qualitative research design. Case study is a methodological approach that uses more than one form of data collection to systematically gather information about how a limited system works and allows in-depth investigation of such limited system (Chmiliar, 2010, p.582).

The WoS database was used in the data collection phase of the study. The keyword "Media Literacy" was searched in research topics in educational research category in the WoS database. "Document title", "abstract", and "keyword" were chosen as search criteria.

In terms of year-based distribution of the studies conducted in the field of media literacy in education, 2018 and 2017 were found to be the years with the most publications, respectively. A holistic evaluation of the years of publication shows that academic studies increased especially as of 2008 and this trend continued in the following years. The literature contains various studies supporting the findings of the present study (Altun, 2014; Aydemir and Erdamar, 2018; Kardaş and Yıldırım, 2017; Kıncal and Korkmaz, 2015; Maden, Maden, and Banaz, 2017). Based on these findings, it can be said that research conducted in Turkey is progressing in parallel with the increase in the studies in other countries.

As to language of publication, English ranks first among academic studies on media literacy indexed in WoS, and it is followed by Spanish and Russian.

Examination based on type of publication indicates that most of the studies are articles, which are followed by papers, book chapters, and reviews, respectively. The literature includes educational research reporting similar findings supporting this finding (Bozdoğan, 2020; Fernández, Lozano, and Cuenca, 2020; Jimenez, Prieto, and Garcia, 2019; Karagöz and Şeref, 2019; Özkaya, 2018; Samul, 2020; Sönmez, 2020). Altun (2014), Kardaş and Yıldırım (2017), and Aydemir and Erdamar (2018) dealing with media literacy also support this finding.

In terms of affiliations of authors publishing research on media literacy, the University of Huelva (Spain), the University of Cantabria (Spain), and the Pennsylvania Commonwealth System of Higher Education (USA), which incorporates many universities, are the top three institutions. 
Examination of the top 10 of the 34 Turkish institutions listed in this category shows that Anadolu University, Afyon Kocatepe University, Çanakkale On Sekiz Mart University, the Turkish Ministry of National Education, and On Dokuz Mayss University are the primary institutions the authors who publish research on media literacy work in or are supported by.

The main sources of publication where studies on media literacy are published as indexed in educational research category in WoS are Comunicar, Inted Proceedings, Edulearn Proceedings, and Reading Research Quarterly. When this finding is compared with the findings concerning the country of publication of journals, it can be said that this ranking is related to the number of studies conducted in the countries on this subject. The findings regarding affiliations also support this.

The USA is one of the primary countries where academic studies on media literacy are published. Spain and the People's Republic of China are the two countries that publish the most studies on media literacy, after the USA, respectively. Turkey ranks in the top ten in this ranking. With only one less publication than the UK and Germany, Turkey ranks sixth in the list.

When the inter-country and inter-institution cooperation is examined through co-authorship analysis of the publications on media literacy, Spain is seen to have the highest degree of cooperation. Following Spain, the USA, China, and England are the three countries with the highest level of cooperation, respectively.

The yearly distribution of the number of citations of academic studies on media literacy indicates that there is no recorded citation information until 1991. While the number of citations was low between 1991 and 2000, it continually increased every passing year after 2000.

As to the keywords used in academic publications on media literacy indexed in educational research category in WoS, the most frequently used ones are "media", "media literacy", "professional consumer", "citizenship education", "media competence", "digital competence", "media in education", "adolescent readers", "social network", "popular culture", and "computer and learning." Examination of the network of keywords indicates that in cluster analysis, academic publications on media literacy are grouped under six clusters. The most frequently used 
keywords in these clusters are "media literacy", "media education", "education", "digital literacy," and "media".

\section{Kaynakça / References}

Altun, A. (2014). Medya okuryazarlığı eğitimine yönelik Türkçe yayınlar: Bir bibliyografya denemesi. Ordu Üniversitesi Sosyal Bilimler Enstitüsü, 08(09), 5-15.

Andres, A. (2009). How to undetake a bibliometric study. Oxford: Chandos Publishing.

Ardıç, E. (2016). Medya okuryazarlığı ile ilgili lisansüstü çalışmaların karşılaştırmalı incelemesi: Türkiye, ABD ve Kanada örneği. Yayımlanmamış yüksek lisans tezi. Bolu Abant İzzet Baysal Üniversitesi Eğitim Bilimleri Enstitüsü, Bolu.

Aufderhe1de, P. and Firestone, C. (1992). Media literacy a report of the national leadership conference on media literacy. Maryland: The Aspen Institute.

Aydemir, S. ve Erdamar, G. (2018). Medya okuryazarlığı eğitimi alanında yapılan çalışmaların tematik, metodolojik ve istatistiksel yönelimleri. Kastamonu Education Journal, 26(4), 1155-1166.

Bozdoğan, K. (2020). A bibliometric analysis of educational studies about "museum". Participatory Educational Research, 7(3), 162-179.

Bozkurt, Ö. Ç. ve Çetin, A. (2015). Girişimcilik ve kalkınma dergisinin bibliyometrik analizi. Girişimcilik ve Kalkınma Dergisi, 11(2), 229-263.

Chadegani, A. A., Salehi, H., Yunus, M., Farhadi, H., Fooladi, M., Farhadi, M., and Ebrahim, N. A. (2013). A comparison between two main academic literature collections: web of science and scopus databases. Asian Social Science, 9(5), 18-26. doi:10.5539/ass.v9n5p18

Chmiliar, L. (2010). Multiple-case designs. Encyclopedia Of Case Study Research, $2,582-584$.

Erdem, C. (2018). Medya okuryazarlığı araştırmalarında eğilimler: Lisansüstü tezlere yönelik bir içerik analizi. Kuramsal Ĕ̆itimbilim Dergisi, 11(4), 693717.

Fernández, J. S., Lozano, A. and Cuenca, C. (2020). Digital citizenship and education: state of the art and bibliometric analysis. 8th International Conference on Information and Education Technology. 
Gümüş, H., Gençoğlu, C. ve Şahin, T. (2020). Physıcal education and sports: Bibliometric analysis of the eric database. International Online Journal of Education and Teaching, 7(4), 1823-1837.

Ivanovića, L. and Hob, Y.-S. (2019). Highly cited articles in the education and educational research category in the social science citation index: A bibliometric analysis. Educational Review, 71(3), 277-286.

Jiménez, C. R., Prieto, M. S. and García, S. A. (2019). Technology and higher education: A bibliometric analysis. Education Sciences, 9(169), 1-9.

Johnson, B. and Christensen, L. (2014). Nitel araştırma. Çev. Edt: S. B. Demir içinde, Eğitim araştırmaları- nicel, nitel ve karma yaklaşımlar (M. Bütün, Çev., s. 375-408). Ankara: Eğiten Kitap.

Julia, J., Supriatna, E., Isrokatun, I., Aisyah, I., Hakim , A. and Odebode, A. A. (2020). Moral education (2010-2019): A bibliometric study. Universal Journal of Educational Research, 8(7), 2954-2968.

Karagöz, B. ve Şeref, İ. (2019). Yunus Emre ile ilgili araştırmaların bibliyometrik analizi. Akdeniz Ĕ̆itim Araştırmaları Dergisi, 27, 123-141.

Kardaş, M. N. ve Yıldırım, Ş. (2017). Medya okuryazarlığı alanında yapılan araştırmalar: bir kaynakça denemesi. Sosyal Bilimler Enstitüsü Dergisi, 34, 1-39.

Kıncal, R. ve Korkmaz, Z. S. (2015). Türkiye'de medya okuryazarlığı üzerine bir değerlendirme. Uluslararası Eğitim Programları ve Öğretim Çalışmaları Dergisi, 5(10), 75-90.

Maden, S., Maden, A. ve Banaz, E. (2017). Medya okuryazarlığı ile ilgili lisansüstü tezlere yönelik bir içerik analizi. International Journal of Languages' Education and Teaching, 5(1), 588-605.

NAMLE. (2020). National Association for Media Literacy Education: 3 Ağustos 2020 tarihinde https://namle.net/publications/media-literacydefinitions/ adresinden erişildi.

Özkaya, A. (2018). Bibliometric analysis of the studies in the field of mathematics education. Educational Research and Reviews, 13(22), 723734.

Özsoy, Z. ve Demir, E. (2018). Which bariatric procedure is the most popular in the world? A bibliometric comparison. Obesity Surgery, 28, 2339-2352.

Pritchard, A. (1969). Statistical bibliography or bibliometrics. Journal Of Documentation, 25(4), 348-349. 
RTÜK. (2021). Medya Okuryazarlığı. 14 Nisan 2021 tarihinde, https://www.medyaokuryazarligi.gov.tr/menu_goster.php?Guid=0A1963B3C923-4759-B793-652B33CE8459\&MenuId=2 adresinden erişildi.

Samul, J. (2020). The research topics of leadership: Bibliometric analysis from 1923 to 2019. International Journal of Educational Leadership and Management, 8(2), 116-143.

Sönmez, Ö. F. (2020). Bibliometric analysis of educational research articles published in the field of social study education based on web of science database. Participatory Educational Research, 7(2), 216-229.

Sönmez, Ö. F. ve Bozdoğan, K. (2020). Bibliometric analysis of values education researches based on web of science database. International Journal of Education Technology and Scientific Researches, 5(13), 1543-1577.

Van Eck, N. J. and Waltman, L. (2013). VOSviewer manual. Leiden: Univeristeit Leiden. 23 Nisan 2021 tarihinde, https://www.vosviewer.com/download/f-33t2.pdf adresinden erişildi.

Wilsdon, J., Allen, L., Belfiore, E., Campbell, P., Curry, S., Hill, S. and Johnson, B. (2015). The metric tide report of the independent review of the role of metrics in research assessment and management. Hefce.

\section{Kaynakça Bilgisi / Citation Information}

Yeşiltaş, E. ve Yılmazer, A. (2021). Eğitimde medya okuryazarlığı ile ilgili araştırmalara yönelik bibliyometrik bir analiz. OPUS-Uluslararası Toplum Araştırmaları Dergisi, 18(Eğitim Bilimleri Özel Sayısı), 49034929. DOI: 10.26466/opus.935547. 